\title{
Intra-arterially infused carbon dioxide-saturated solution for sensitizing the anticancer effect of cisplatin in a rabbit VX2 liver tumor model
}

\author{
NAOTO KATAYAMA ${ }^{1}$, KOJI SUGIMOTO ${ }^{1}$, TAKUYA OKADA ${ }^{1}$, TAKESHI UEHA ${ }^{2,3}$, \\ YOSHITADA SAKAI ${ }^{2}$, HIDEO AKIYOSHI ${ }^{4}$, KEIICHIRO MIE ${ }^{4}$, EISUKE UESHIMA ${ }^{1}$, KEITARO SOFUE ${ }^{1}$, \\ YUTAKA KOIDE $^{1}$, RYUICHIRO TANI ${ }^{1}$, TOMOYUKI GENTSU ${ }^{1}$ and MASATO YAMAGUCHI ${ }^{1}$ \\ ${ }^{1}$ Department of Radiology and Center for Endovascular Therapy, Kobe University Hospital, Chuo-ku, Kobe 650-0017; \\ ${ }^{2}$ Division of Rehabilitation Medicine, Kobe University Graduate School of Medicine, Chuo-ku, Kobe 650-0017; \\ ${ }^{3}$ NeoChemir Inc., Chuo-ku, Kobe 651-0087; ${ }^{4}$ Laboratory of Veterinary Surgery, Department of Graduate School \\ of Life and Environmental Sciences, Osaka Prefecture University, Izumisano, Osaka 598-8531, Japan
}

Received January 30, 2017; Accepted June 2, 2017

DOI: $10.3892 /$ ijo.2017.4056

\begin{abstract}
The present study aimed to evaluate the efficacy of an intra-arterially infused carbon dioxide $\left(\mathrm{CO}_{2}\right)$-saturated solution in sensitizing the anticancer effect of cisplatin in a rabbit VX2 liver tumor model. Forty VX2 liver tumor-bearing Japanese white rabbits were randomly divided into four groups and infused via the proper hepatic artery with a saline solution (control group), $\mathrm{CO}_{2}$-saturated solution $\left(\mathrm{CO}_{2}\right.$ group), cisplatin solution (cisplatin group), or $\mathrm{CO}_{2}$-saturated solution and cisplatin solution (combined group). The tumor volume (TV) and the relative tumor volume $(\mathrm{RTV}), \mathrm{RTV}=(\mathrm{TV}$ on day 3 or 7$) /(\mathrm{TV}$ on day 0$) \times 100$, were calculated using contrastenhanced computed tomography. Hypoxia-inducible factor-1 $\alpha$ (HIF-1 $\alpha$ ) and carbonic anhydrase IX (CA IX) staining were used to evaluate cellular hypoxia. Cleaved caspase- 3 and cleaved caspase- 9 were analyzed to assess tumor apoptosis. The mean RTV on days 3 and 7 were $202.6 \pm 23.7$ and $429.2 \pm 94.8 \%$, respectively, in the control group; $172.2 \pm 38.1$ and $376.5 \pm 61.1 \%$ in the $\mathrm{CO}_{2}$ group; $156.1 \pm 15.1$ and $269.6 \pm 45.2 \%$ in the cisplatin group; and $118.3 \pm 28.1$ and $210.3 \pm 55.1 \%$ in the combined group. RTV was significantly lower in the $\mathrm{CO}_{2}$ group than in the control group (day $3 ; \mathrm{P}<0.05$ ), and in the combined group than in the cisplatin group (days 3 and 7; $\mathrm{P}<0.05$ ). HIF-1 $\alpha$ and CA IX suppression, and increased cleaved caspase- 3 and
\end{abstract}

Correspondence to: Dr Naoto Katayama, Department of Radiology and Center for Endovascular Therapy, Kobe University Hospital, 7-5-2 Kusunoki-cho, Chuo-ku, Kobe 650-0017, Japan E-mail: katay7010@gmail.com

Abbreviations: $\mathrm{CO}_{2}$, carbon dioxide; DAPI, 4',6-diamidino-2phenylindole; HIF-1 $\alpha$, hypoxia-inducible factor- $1 \alpha$; CA IX, carbonic anhydrase IX

Keywords: intra-arterial infusion, $\mathrm{CO}_{2}$-saturated solution, cisplatin sensitizer, VX2 tumor cleaved caspase- 9 expression, were detected in the $\mathrm{CO}_{2}$ and combined groups, compared with the other two groups. An intra-arterially infused $\mathrm{CO}_{2}$-saturated solution inhibits liver VX2 tumor growth and sensitizes the anticancer effect of cisplatin.

\section{Introduction}

Solid tumors constitute approximately $90 \%$ of all known types of cancer (1). The rapid growth of such tumors alters the cellular microenvironment because of an inadequate oxygen supply and results in hypoxia $(2,3)$. Tumor hypoxia is a potential therapeutic problem because of its adverse impact on the effectiveness of chemotherapy. Carbon dioxide $\left(\mathrm{CO}_{2}\right)$ therapy has historically been used for its therapeutic effect on skin problems (4-6). The mechanisms of this beneficial effect are an increase in blood flow and microcirculation, nitric oxidedependent neocapillary formation, and a partial increase in oxygen pressure in the local tissue, known as the Bohr effect (7). The anticancer effect of the transcutaneous application or intra-arterial infusion of $\mathrm{CO}_{2}$ has been reported (8-11). In a recent study, the transcutaneous application of $\mathrm{CO}_{2}$ enhanced the therapeutic efficacy of doxorubicin for human malignant fibrous histiocytoma (12). There is similarly a possibility that the intra-arterial infusion of $\mathrm{CO}_{2}$ may enhance the therapeutic effect of intra-arterial infusion chemotherapy, but this is unknown.

We evaluated whether the intra-arterial infusion of a $\mathrm{CO}_{2}$-saturated solution would sensitize the anticancer effect of cisplatin, and we elucidated the mechanism of this therapy in a rabbit VX2 liver tumor model.

\section{Materials and methods}

The VX2 liver tumor model. The present study was approved by the Institutional Animal Care and Use Committee (Permission no. P-150202) on February 20, 2015 and was carried out according to the Kobe University Animal Experimentation 
Regulations. Forty Japanese white rabbits (age, 3-4 months old; mean body weight, $2.62 \pm 0.03 \mathrm{~kg}$ ) were implanted with fresh VX2 tumors by injecting $0.1 \mathrm{ml}$ of a VX2 tumor tissue suspension (provided by Japan SLC, Inc., Shizuoka, Japan) into their livers 3 weeks before the intra-arterial infusion. Subsequently, the rabbits were randomly divided into four groups: the control group, the $\mathrm{CO}_{2}$ group, the cisplatin group and the combined group, with 10 in each group. Each material was infused as follows: saline solution into the control group, $\mathrm{CO}_{2}$-saturated solution into the $\mathrm{CO}_{2}$ group, both cisplatin solution and saline solution into the cisplatin group, and both $\mathrm{CO}_{2}$-saturated solution and cisplatin solution into the combined group. For the following procedures, each rabbit was anesthetized with sodium pentobarbital (maximum dose of $50 \mathrm{mg} / \mathrm{kg}$; Somnopenthyl; Kyoritsu Seiyaku, Tokyo, Japan) via a marginal ear vein.

Preparation of materials for infusion. The $\mathrm{CO}_{2}$-saturated solution at $\mathrm{pH} 4.0$ was prepared as previously described (8). The cisplatin solution was prepared by dissolving DDP-H (a fine-powder formulation of cisplatin, IA-call; Nippon Kayaku Co., Ltd., Tokyo, Japan) into the saline solution to a concentration of $1.5 \mathrm{mg} / \mathrm{ml}$. The dose of the $\mathrm{CO}_{2}$-saturated solution and the saline solution was $50 \mathrm{ml}$ each, and the dose of cisplatin was $1.75 \mathrm{mg} / \mathrm{kg}$ (as determined from the unpublished data of a DDP-H animal experiment by Nippon Kayaku).

The CT examination. Contrast-enhanced CT (Toshiba Activion 16 TXS-031A; Toshiba Medical Systems, Tochigi, Japan or Rm-CT2; Rigaku, Tokyo, Japan) was performed to evaluate the size of the tumor in the liver. The CT scan was initiated $55 \mathrm{sec}$ after the injection of the contrast medium (Omnipaque 300; Daiichi Sankyo, Tokyo, Japan) at a rate of $0.3 \mathrm{ml} / \mathrm{sec}$ via a marginal ear vein. The amount of contrast medium used was set to $2.0 \mathrm{ml} / \mathrm{kg}$. Contrast-enhanced CT was performed before the procedure and 3 and 7 days after the procedure.

Intra-arterial infusion procedure. After the CT examination, intra-arterial infusion was performed with a $\mathrm{C}$-arm device (SIREMOBIL Compact L; Siemens Medical Solutions, Erlangen, Germany or ARCADIS Varic; Siemens-Asahi Medical Technologies, Tokyo, Japan). The right femoral artery was exposed and directly punctured with a 22-gauge needle (SURFLO intravenous catheter; Terumo, Tokyo, Japan). A 0.018-inch nitinol guidewire (Cook Medical Japan, Tokyo, Japan) was placed through the needle, and a 4-French introducer catheter (Micropuncture introducer catheter; Cook Medical Japan) was inserted over the guidewire. After the tip of a 2.4-French microcatheter with a swan-neck shape (Nadeshiko; JMS, Co., Ltd., Hiroshima, Japan) was placed into the proper hepatic artery, digital subtraction angiography was performed to confirm the distribution of contrast medium to the liver by manually injecting $1 \mathrm{ml}$ of contrast medium at a rate of $0.1 \mathrm{ml} / \mathrm{s}$ (Fig. 1). Each material of the group, as described above, was infused after the angiography. The $\mathrm{CO}_{2}$-saturated solution and the saline solution were infused for $10 \mathrm{~min}$, and the cisplatin solution was administered for 3 min through the catheter. After the injection of the solution, the catheter was removed, and the right femoral artery was ligated to achieve hemostasis. The incision wound was sutured, and the rabbits

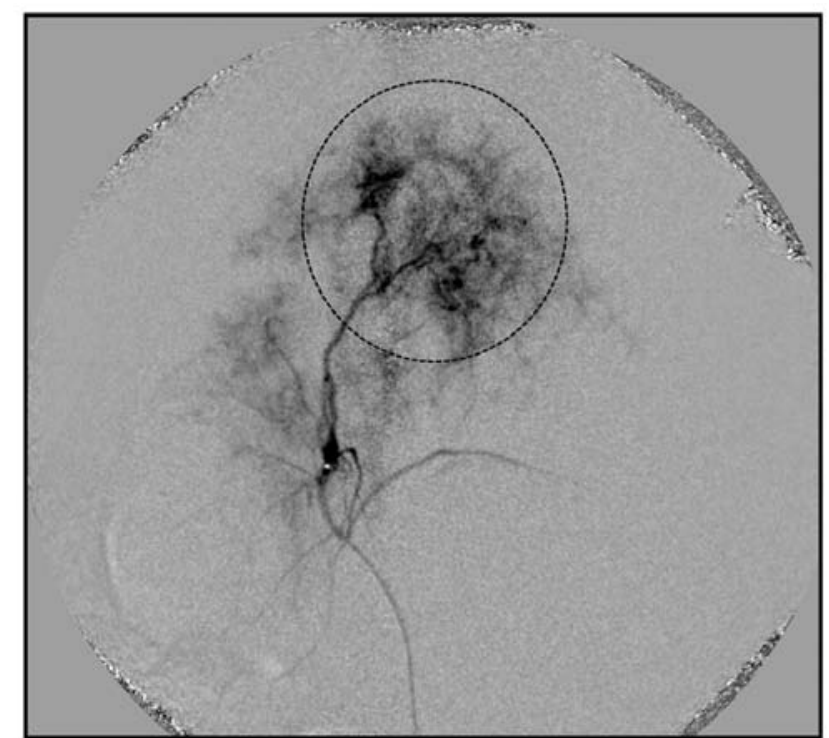

Figure 1. Hepatic angiography. Digital subtraction angiography of the proper hepatic artery shows staining of the implanted hepatic tumor (dotted line circle).

were observed for 7 days while maintaining a normal feeding regimen. All rabbits were euthanized after CT scanning on day 7 , and the liver of each rabbit was carefully excised and processed for histological examination.

Tumor growth and volume measurement. All recorded CT volumetric data were transferred to Ziostation software (Ziosoft, Inc., Tokyo, Japan) and reconstructed in 3-mm thick slices. Two experienced radiologists, who were blinded to the treatment group status, manually traced the contour of the VX2 tumor area in each slice. All measurements were independently performed twice, and the tumor area was determined as the mean value of all measurements. The tumor volume (TV) was then calculated using the following formula: $\mathrm{TV}=$ the total circumscribed area in each slice $\mathrm{x} C \mathrm{~T}$ section thickness. The relative tumor volume (RTV) was calculated as follows: $\mathrm{RTV}=(\mathrm{TV}$ on day 3 or 7$) /(\mathrm{TV}$ on day 0$) \times 100$. We evaluated whether the therapeutic effect of the combined group was antagonistic, additive or synergistic by comparing with expected RTV for additive effect. Expected RTV for additive effect was calculated based on the following formula: expected RTV for additive effect $=\left(\mathrm{RTV}\right.$ of the $\mathrm{CO}_{2}$ group) $\mathrm{x}$ (RTV of the cisplatin group)/(RTV of the control group), as reported (13).

Histology. Liver tissue was fixed in a $10 \%$ phosphate-buffered formaldehyde solution, and 7-mm sections were obtained and embedded in paraffin. Serial sections were then cut at $6-\mu \mathrm{m}$ thickness. One section was stained with hematoxylin and eosin (H\&E) and contiguous sections were immunofluorescently stained using 4',6-diamidino-2-phenylindole (DAPI) stain and APO-Direct kit (Bay Bioscience, Co., Ltd., Kobe, Japan) to evaluate DNA fragmentation. Immunofluorescence assay of DNA fragmentation is described below. All histopathologic specimens were evaluated by a pathologist under a light microscope (Keyence Corp., Osaka, Japan) and the apoptotic area was described, based on the fluorescence staining results. 
Immunofluorescence assay of DNA fragmentation. APO-Direct kit is a single-step staining method for labeling DNA breaks to detect apoptotic cells by flow cytometry. A method which is often used to detect fragmented DNA utilizes a reaction catalyzed by exogenous TdT, often referred to as 'end-labeling' or 'TUNEL' (terminal deoxynucleotidyltransferase dUTP nick end labeling). The APO-Direct kit was used for DNA fragmentation with immunofluorescence staining according to the manufacturer's protocol. Solid specimens of tumors were minced and filtered through a cell strainer (BD Falcon; BD Biosciences, Bedford, MA, USA) to obtain a single cell suspension from implanted tumors. Erythrocytes were lysed in BD Pharm Lyse ${ }^{\mathrm{TM}}$ lysing buffer (Bay Bioscience), and the remaining cells were pelleted and resuspended in phosphatebuffered saline (PBS) solution. Single-cell suspensions were fixed with $1 \%$ (vol/vol) paraformaldehyde and resuspended in $70 \%(\mathrm{vol} / \mathrm{vol})$ ice-cold ethanol at a concentration of $1 \times 10^{6}$ cells $/ \mathrm{ml}$. Each cell pellet was resuspended in $50 \mathrm{ml}$ of DNA labeling solution (reaction buffer, $10 \mu \mathrm{l}$; terminal deoxynucleotidyl transferase enzyme, $0.75 \mu \mathrm{l}$; fluorescein isothiocyanate, $2^{2}$-deoxyuridine, 5'-triphosphate, $0.8 \mu \mathrm{l}$; distilled $\mathrm{H}_{2} \mathrm{O}, 32.25 \mu \mathrm{l}$ ) and incubated for $60 \mathrm{~min}$ at $37^{\circ} \mathrm{C}$.

Immunohistochemistory. The immunohistochemical expression of hypoxia-inducible factor- $1 \alpha(\mathrm{HIF}-1 \alpha)$ and carbonic anhydrase IX (CA IX) as intrinsic markers of tumor hypoxia were detected using anti-HIF-1 $\alpha$ antibody (1:100, H1alpha67; Abcam PLC, Cambridge, UK) and anti-CA IX antibody (1:100; Novus Biologicals LLC, Littleton, CO, USA). Deparaffinized sections were digested with proteinase (Dako Retrieval Solution Ready-to-Use) for $10 \mathrm{~min}$ and treated overnight at $4^{\circ} \mathrm{C}$ with the antibodies in Can Get Signal immunostain solution. Following the treatment, sections were incubated with horseradish peroxidase (HRP)-conjugated goat anti-mouse IgG polyclonal antibody (Nichirei Bioscience, Tokyo, Japan) for $30 \mathrm{~min}$ at room temperature. The signal was developed as a brown reaction product using the peroxidase substrate 3,3'-diaminobenzidine (Nichirei Bioscience). Sections were counter stained with hematoxylin, and were captured under a microscope. Moreover, to evaluate the quantification of HIF-1 $\alpha$ expression, the secondary antibody goat anti-mouse immunoglobulin Alexa Fluor 596 (1:200 dilution; Life Technologies, Carlsbad, CA, USA) was used for $100 \mathrm{~min}$ at room temperature. Immunofluorescence nuclear staining using DAPI was performed to quantify HIF-1 $\alpha$ expression. The numbers of hypoxic cells were counted directly in four randomly selected fields and averaged. Images were acquired using a fluorescence microscope (BZ-X700; Keyence).

Immunoblot analysis for caspase-3 and caspase-9 assay. Immunoblot analysis was performed to evaluate the apoptotic pathway of caspase-3 and caspase-9. Tumor lysates were prepared from tumor tissues in whole-cell lysis buffer (Mammalian Protein Extraction Reagent; Thermo Fisher Scientific, Rockford, IL, USA). Samples were processed with standard western immunoblotting procedures. Membranes were incubated overnight at $4^{\circ} \mathrm{C}$ with the following antibodies in Can Get Signal Solution 1 (Toyobo, Co., Ltd., Osaka, Japan): caspase-3 antibody (1:1,000; Cell Signaling Technology, Danvers, MA, USA), anti-cleaved caspase- 9 antibody (1:1,000;
Table I. The tumor volumes $\left(\mathrm{mm}^{3}\right)$ and the relative tumor volume $(\%)$ on days 0,3 and 7 .

\begin{tabular}{lccr}
\hline Group & Day 0 & Day 3 & \multicolumn{1}{c}{ Day 7 } \\
\hline $\begin{array}{l}\text { Control } \\
(\mathrm{n}=10)\end{array}$ & $2,669.2 \pm 496.7$ & $5,378.0 \pm 1034.5$ & $11,267.4 \pm 2344.7$ \\
$\mathrm{CO}_{2}$ & $2,704.3 \pm 59.22$ & $4,670.3 \pm 1500.6$ & $10,215.5 \pm 3092.6$ \\
$(\mathrm{n}=10)$ & & $(172.2 \pm 38.1 \%)$ & $(376.5 \pm 61.1 \%)$ \\
Cisplatin & $2,849.4 \pm 918.4$ & $4,442.8 \pm 1565.4$ & $7,786.0 \pm 3242.6$ \\
$(\mathrm{n}=10)$ & & $(156.1 \pm 15.1 \%)$ & $(269.6 \pm 45.2 \%)$ \\
Combined & $2,981.1 \pm 873.5$ & $3,445.9 \pm 968.0$ & $6,005.1 \pm 1409.0$ \\
$(\mathrm{n}=10)$ & & $(118.3 \pm 28.1 \%)$ & $(210.3 \pm 55.1 \%)$ \\
Expected & & $(132.9 \pm 27.3 \%)$ & $(252.3 \pm 99.2 \%)$ \\
RTV & & & \\
\hline
\end{tabular}

The tumor volumes (TV) and the relative tumor volume (RTV) are expressed as the mean \pm the standard deviation. The values of RTV are enclosed in parentheses. RTV was calculated based on the following formula: $\mathrm{RTV}=(\mathrm{TV}$ on day 3 or 7$) /(\mathrm{TV}$ on day 0$) \times 100 . \mathrm{CO}_{2}$, carbon dioxide.

Cell Signaling Technology) and $\alpha$-tubulin antibody $(1: 2,000$; Sigma-Aldrich, St. Louis, MO, USA). After washing, the membranes were incubated with the appropriate secondary antibody conjugated to horseradish peroxidase, and exposed using the ECL Plus western blotting detection system (GE Healthcare Bio-Sciences, Piscataway, NJ, USA). A chemilumino analyzer (LAS-3000 mini; Fujifilm, Tokyo, Japan) was used to detect signals.

Statistical analysis. Statistical analyses were conducted using JMP 12.0.1 (SAS Institute, Inc., Cary, NC, USA). The data are presented as the mean \pm standard deviation, unless indicated otherwise. The significance of differences between groups was evaluated using the two-tailed Student's t-test, and by one-way analysis of variance with post-hoc Tukey's honestly significant difference test for multiple comparisons. $\mathrm{P}<0.05$ was considered significant.

\section{Results}

All procedures were performed successfully, and all rabbits survived for 1 week after the procedure. The rabbits were euthanized on day 7, and the liver of each rabbit was excised and processed for histological examination. The mean body weight on the procedure day and on day 7 were, respectively, $2.76 \pm 0.18$ and $2.78 \pm 0.19 \mathrm{~kg}$ in the control group; $2.66 \pm 0.23$ and $2.70 \pm 0.23 \mathrm{~kg}$ in the $\mathrm{CO}_{2}$ group; $2.62 \pm 0.16$ and $2.64 \pm 0.16 \mathrm{~kg}$ in the cisplatin group; and $2.58 \pm 0.08$ and $2.59 \pm 0.07 \mathrm{~kg}$ in the combined group. There were no significant differences among the four groups $(\mathrm{P}>0.05)$.

Tumor growth and volume measurement. Contrast-enhanced CT of liver tumors demonstrated low-attenuation lesions with peripheral enhancement (Fig. 2). The mean TV and RTV on days 3 and 7 are shown in Table I. The line graph of the mean 


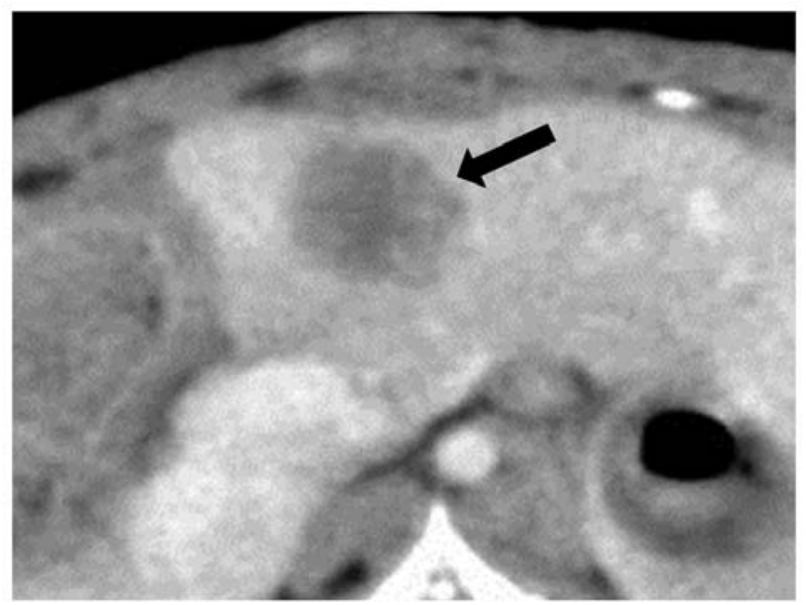

Figure 2. Contrast-enhanced CT imaging after the procedures of an animal from the combined group on day 0 shows a low-attenuation lesion (arrow).

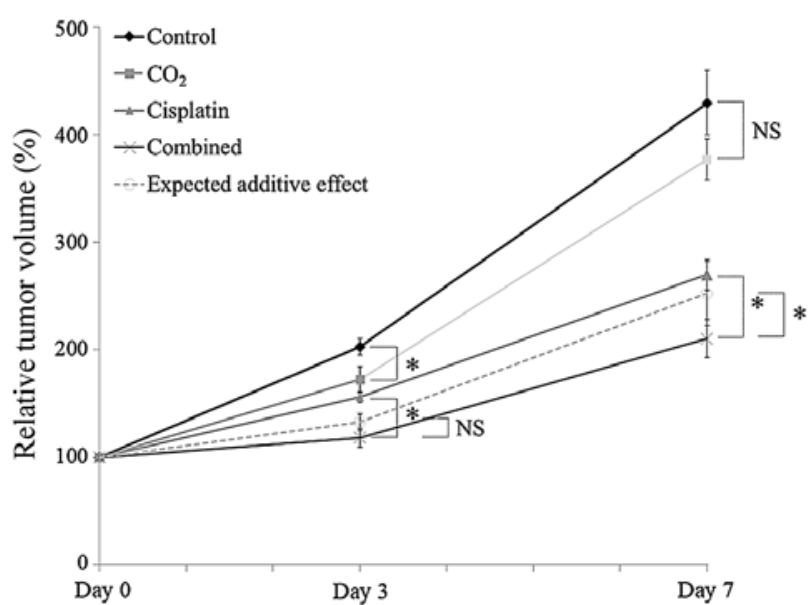

Figure 3. The mean relative tumor volume on days 3 and 7 . The relative tumor volume (RTV) on day 3 was significantly lower in the $\mathrm{CO}_{2}$ group than in the control group $(\mathrm{P}<0.05)$, but there was no significant difference on day 7 $(\mathrm{P}=0.16)$. RTV on days 3 and 7 was significantly lower in the combined group than in the cisplatin group $(\mathrm{P}<0.05)$. The mean RTV on day 7 was also significantly lower than expected RTV for additive effect $(\mathrm{P}<0.05)$. RTV was calculated based on the following formula: RTV $=(\mathrm{TV}$ on day 3 or 7$) /(\mathrm{TV}$ on day 0) x 100. The mean tumor volumes and RTV are also presented. $\mathrm{CO}_{2}$, carbon dioxide; NS, not significant. ${ }^{*} \mathrm{P}<0.05$.

RTV is shown in Fig. 3. The mean RTV of the $\mathrm{CO}_{2}$ group on day 3 was significantly decreased, compared with the control group $(\mathrm{P}<0.05)$; however, this ratio showed no significant difference on day $7(\mathrm{P}=0.16)$. The mean $\mathrm{RTV}$ on days 3 and 7 of the combined group was significantly lower than that in the cisplatin group $(\mathrm{P}<0.05)$. The mean RTV on day 7 was also significantly lower than expected RTV for additive effect $(\mathrm{P}<0.05)$.

Evaluation of apoptosis. Representative H\&E-stained liver sections demonstrated an increased apoptotic area and decreased tumor area in the $\mathrm{CO}_{2}$ group, cisplatin group, and combined group, compared with the control group (Fig. 4). Immunoblot analyses showed higher expression of cleaved caspase- 3 and caspase- 9 in the $\mathrm{CO}_{2}$ and combined groups than in the control and cisplatin groups (Fig. 5).

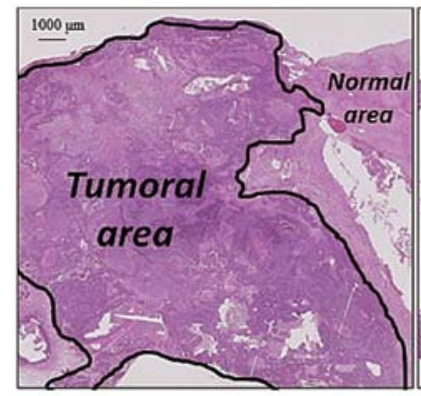

Control

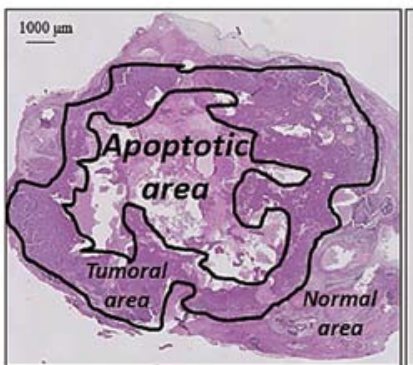

Cisplatin

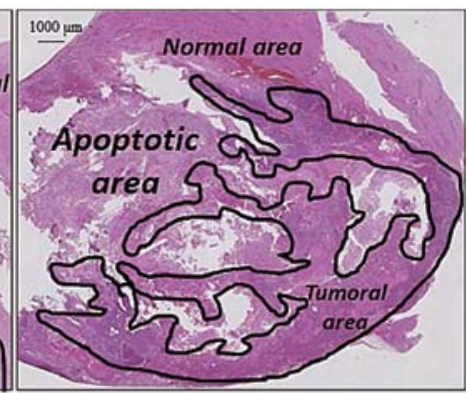

$\mathrm{CO}_{2}$

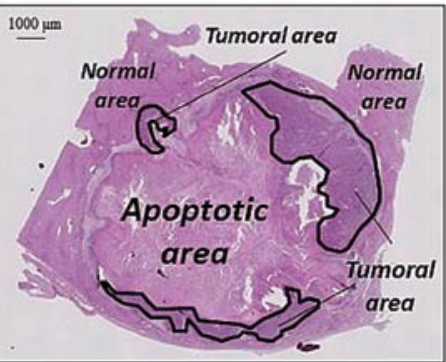

Combined
Figure 4. Histological findings of liver sections on day 7. The hematoxylin and eosin-stained section of a liver demonstrates an increased apoptotic area and decreased tumoral area in the $\mathrm{CO}_{2}$ and cisplatin groups, and more so in the combined group, compared with the control group. The scale bars indicate $1,000 \mu \mathrm{m} . \mathrm{CO}_{2}$, carbon dioxide.

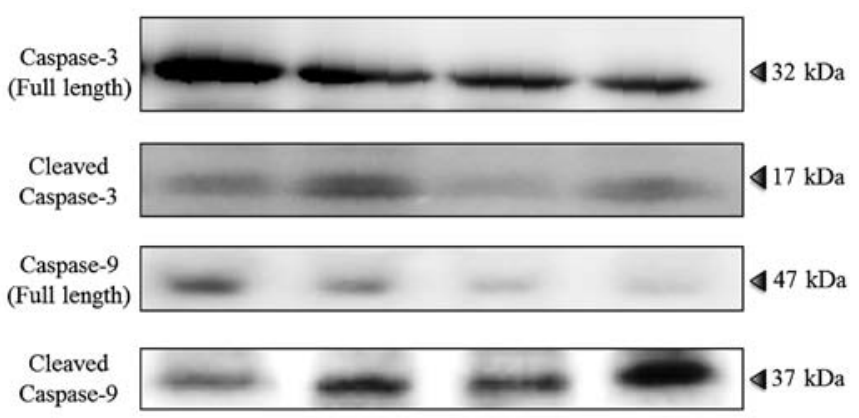

Figure 5. Immunoblot analysis of liver sections on day 7. Immunoblot analysis shows greater expression of cleaved caspase- 3 and cleaved caspase- 9 in the carbon dioxide $\left(\mathrm{CO}_{2}\right)$ group and the combined group than in the control and cisplatin groups.

Evaluation of hypoxia. HIF-1 $\alpha$ and CA IX staining demonstrated suppression of HIF- $1 \alpha$ and CA IX in the $\mathrm{CO}_{2}$ and combined group (Fig. 6A and 6B). As for the quantification of HIF- $1 \alpha$ expression, the numbers of hypoxic cells per area were $246 \pm 118$ in the control group, $21 \pm 10.4$ in the $\mathrm{CO}_{2}$ group, $152 \pm 40.7$ in the cisplatin group and $16 \pm 7.3$ in the combined group. Hypoxic cells were significantly more in the control and cisplatin groups compared with the $\mathrm{CO}_{2}$ and combined groups (Fig. 6C and 6D; $\mathrm{P}<0.05$ ).

\section{Discussion}

There was a significant difference in tumor growth between the control group and the $\mathrm{CO}_{2}$ group, and between the cisplatin group and the combined group. The intra-arterial infusion of the $\mathrm{CO}_{2}$-saturated solution inhibited tumor growth and 


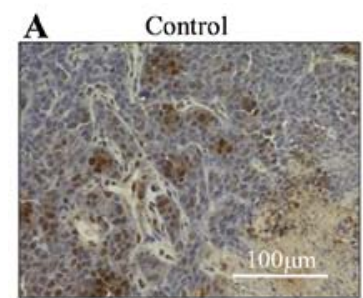

Cisplatin

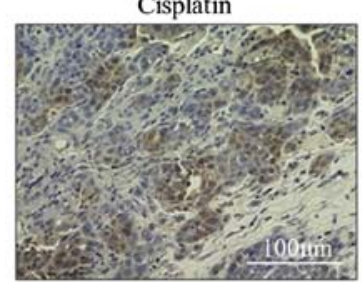

C

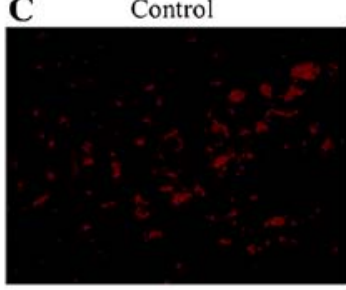

Cisplatin

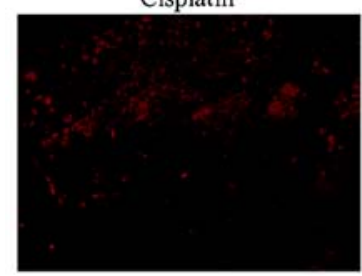

$\mathrm{CO}_{2}$

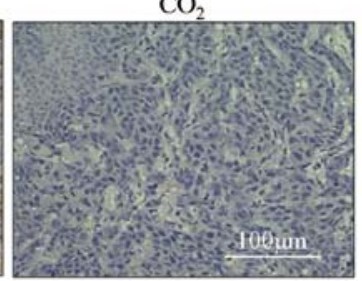

Combined

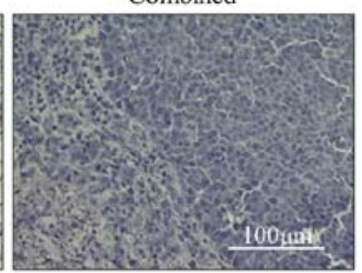

$\mathrm{CO}_{2}$

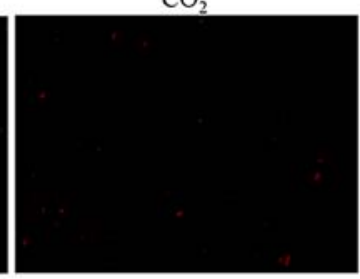

Combined

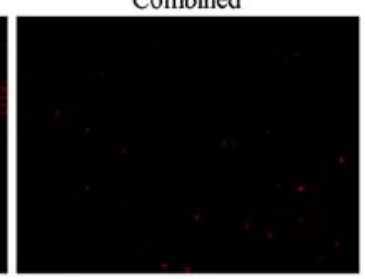

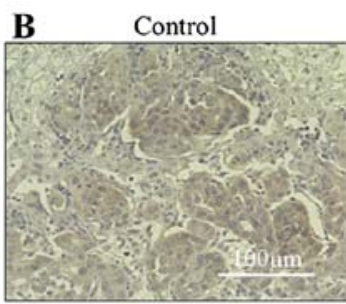

Cisplatin
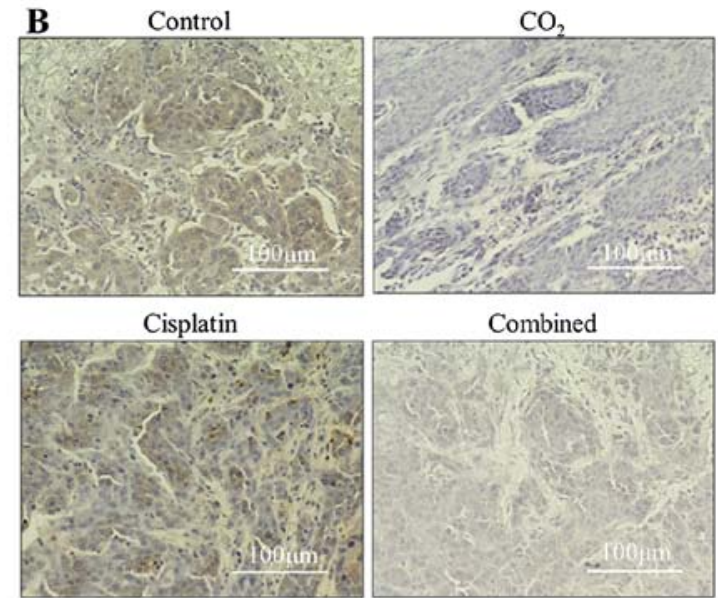

Combined
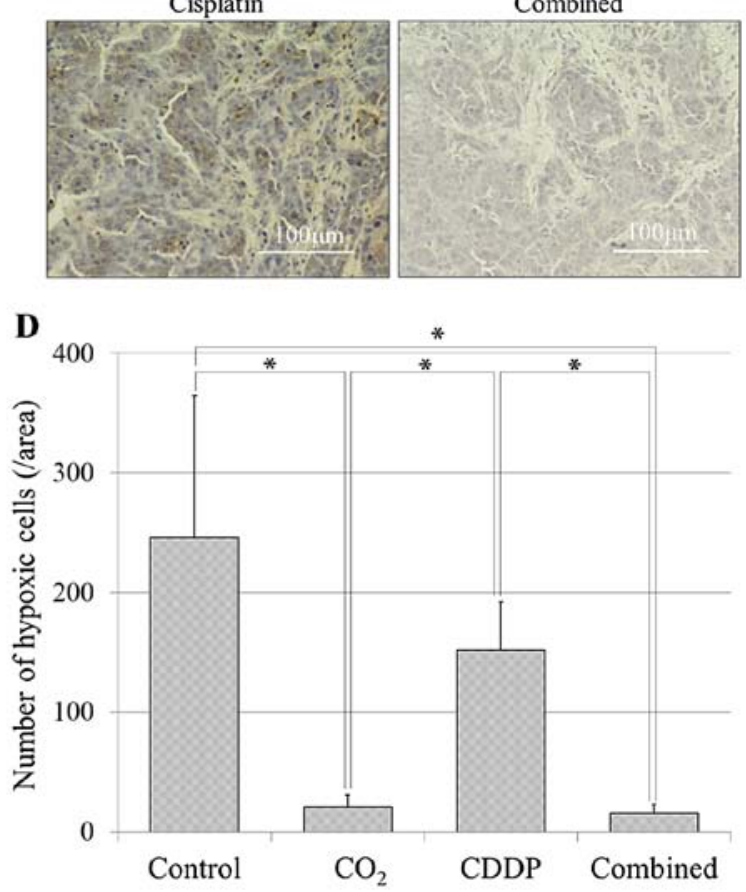

Figure 6. Hypoxic cell expression of liver sections on day 7. (A) Immunohistochemical analysis of hypoxia-inducible factor-1 $\alpha$ (HIF-1 $\alpha$ ) expression (stained brown) in liver sections on day 7. The scale bars indicate $100 \mu \mathrm{m}$. (B) Immunohistochemical analysis of carbonic anhydrase IX (CA IX) expression (stained brown) in liver sections on day 7. The scale bars indicate $100 \mu \mathrm{m}$. (C) Immunofluorescence assay of HIF-1 $\alpha$ shows the hypoxic cells stained red. (D) The histogram displays the number of hypoxic cells per area counted directly by immunofluorescence staining. Hypoxic cells are expressed in tumors in the control and the cisplatin groups, and decreased in the carbon dioxide $\left(\mathrm{CO}_{2}\right)$ and the combined groups $\left({ }^{*} \mathrm{P}<0.05\right)$.

sensitized the anticancer effect of cisplatin. The results of this study will contribute to improving the therapeutic effect of intra-arterial chemotherapy using cisplatin.

$\mathrm{CO}_{2}$ effect of improving hypoxia and inducing apoptosis have been explained by some mechanisms. The first mechanism is direct antitumor effect of $\mathrm{CO}_{2}$. There are several reports showing that intracellular calcium (i.e., $\mathrm{Ca}^{2+}$ ) concentrations increased by $\mathrm{CO}_{2}$ induces the expression of peroxisome proliferator-activated receptor gamma coactivator-1 alpha and mitochondrial biogenesis (14-19). In vivo study of a human malignant fibrous hystiocytoma tumor model, transcutaneous $\mathrm{CO}_{2}$ treatment increased intracellular $\mathrm{Ca}^{2+}$ concentrations and induced mitochondrial DNA apoptosis (12). In vitro study of a human neuroblastoma cell model, intracellular reactive oxygen species induced by $\mathrm{CO}_{2}$ intracellular reactive oxygen species, lead to proapoptotic p53 signal stimulation, DNA damage, and cell death through the mitochondrial pathway (20). The second and third possible mechanisms are related to oxygenation and $\mathrm{pH}$ in the tumor microenvironment. The present study did not show evidence of increased partial pressure of oxygen or oxygen saturation and decreased $\mathrm{pH}$ in $\mathrm{VX} 2$ tumor tissue during the procedure. However, a previous study (8) demonstrated that transcuta- neous $\mathrm{CO}_{2}$ application significantly lowers intracellular $\mathrm{pH}$, decreases oxyhemoglobin, and increases deoxyhemoglobin in treated muscle.

$\mathrm{CO}_{2}$ therapy is considered to improve tumor hypoxia and induce the mitochondrial pathway of apoptosis as described above. Moreover, this therapy was reported to suppress vascular endothelial growth factor and HIF-1 $\alpha$ (21). In this study, there was less HIF-1 $\alpha$ expression and more cleaved caspase- 3 and caspase- 9 expression in the $\mathrm{CO}_{2}$ and combined groups than in the control and cisplatin groups. This result revealed that intra-arterial $\mathrm{CO}_{2}$ infusion could improve hypoxia and induce apoptosis in tumors. Caspase-3 is activated in apoptotic cells by the extrinsic (i.e., death ligand) and intrinsic (i.e., mitochondrial) pathways and caspase-9 reflects mitochondrial apoptosis. Cleaved caspase -3 and cleaved caspase- 9 are activated forms of caspase-3 and caspase-9, and are commonly used to detect apoptosis (22). HIF-1 $\alpha$ is a basic helix-loop-helix-PAS (bHLH-PAS) transcription factor that has an essential role in $\mathrm{O}_{2}$ homeostasis $(6,7,9,10)$, and has recently emerged as a major factor influencing tumor proliferation and malignant progression $(23,24)$. Hypercapnia was reported to counter-regulate the activation of the HIF pathway by reducing the intracellular $\mathrm{pH}(25)$. 
Minimizing hypoxia and suppression of HIF-1 $\alpha$ expression in tumors also has the potential to enhance chemotherapeutic effects (26). In this study, the combined group achieved a higher tumor growth inhibition rate, compared with the other groups and expected additive effect. We expected that a $\mathrm{CO}_{2}$-saturated solution would sensitize the tumor to the antitumor effect of cisplatin by suppressing HIF-1 $\alpha$ expression. Previous reports support our hypothesis: Ai et al (27) revealed that the genetic knockdown of HIF-1 $\alpha$ or pharmacological promotion of HIF-1 $\alpha$ degradation enhanced the response of ovarian cancer cells to cisplatin, and diindolylmethane is reportedly a cisplatin sensitizer that exerts its effect by targeting signal transducer and activator of transcription 3, which suppresses HIF-1 $\alpha$ and vascular endothelial growth factor (28).

Intra-arterial infusion of $\mathrm{CO}_{2}$ is well-known to interventional radiologists as a negative contrast medium. $\mathrm{CO}_{2}$ has advantages over other treatments, such as its lack of nephrotoxic and allergenic effects on the human body. Moreover, it is markedly less expensive than other drugs (the typical cost for $\mathrm{CO}_{2}$ is 3 cents per $100 \mathrm{ml}$ ) (29). Thus, we believe that a $\mathrm{CO}_{2}$-saturated solution is the ideal material for sensitizing the anticancer effect of intra-arterial cisplatin infusions. The infusion volume of the $\mathrm{CO}_{2}$-saturated solution was set to $50 \mathrm{ml}$; approximately $38 \mathrm{ml}$ of $\mathrm{CO}_{2}$ gas was dissolved in the $\mathrm{CO}_{2}$-saturated solution (calculated using a solubility limit of 1,508 parts per million at $\left.1 \mathrm{~atm}, 25^{\circ} \mathrm{C}\right)$. Thus, the $\mathrm{CO}_{2}$ gas was injected at a dose of 12.6-16.2 $\mathrm{ml} / \mathrm{kg}$ without severe complications, although hepatic isozymes were not measured. A previous report described a rabbit experimental model of intra-arterial $\mathrm{CO}_{2}$ gas injection at a dose of $10 \mathrm{ml} / \mathrm{kg}$ in which no subacute hepatic adverse effects were observed (30).

There are several limitations to the present study. First, VX2 tumors can easily be implanted into other organs, allowing for the investigation of many interventional procedures. However, this model does not represent the complexity or size of human liver cancer (31). VX2 tumors grow rapidly and have been reported to contain large areas of liquefaction necrosis beyond 15 days after implantation (32). We assume that the large standard deviation of TV in this study was mainly caused by this VX2 tumor characteristic. Larger sample sizes may be needed to decrease the standard deviation. Functional imaging, such as perfusion CT and magnetic resonance spectroscopy, have been used to evaluate tumor angiogenesis and necrotic changes of VX2 tumors $(33,34)$; however, these examinations were not performed because our laboratory lacks these facilities. This study was a pilot animal investigation to assess the effect of a $\mathrm{CO}_{2}$-saturated solution; therefore, only a single infusion and a single dose were used. More $\mathrm{CO}_{2}$ doses may need to be assessed to achieve a stronger antitumor effect, which was suggested by a previous report in which $\mathrm{CO}_{2}$ was administered twice weekly by transcutaneous application (9).

In conclusions, intra-arterial infusion of a $\mathrm{CO}_{2}$-saturated solution should inhibit tumor growth and sensitize the anticancer effect of cisplatin by suppressing HIF-1 $\alpha$ expression in a rabbit VX2 liver tumor model.

\section{Acknowledgements}

The authors would like to thank Editage (www.editage.jp) for English language editing. Dr M. Yamaguchi reports grants from Grant-in-Aid for Scientific Research (C) from the Japan Society for the Promotion of Science.

\section{References}

1. Mees G, Dierckx R, Vangestel C and Van de Wiele C: Molecular imaging of hypoxia with radiolabelled agents. Eur J Nucl Med Mol Imaging 36: 1674-1686, 2009.

2. Laking G and Price P: Radionuclide imaging of perfusion and hypoxia. Eur J Nucl Med Mol Imaging 37 (Suppl 1): S20-S29, 2010.

3. Vaupel P: The role of hypoxia-induced factors in tumor progression. Oncologist 9 (Suppl 5): 10-17, 2004.

4. Mimeault M and Batra SK: Hypoxia-inducing factors as master regulators of stemness properties and altered metabolism of cancer- and metastasis-initiating cells. J Cell Mol Med 17: 30-54, 2013.

5. Hartmann BR, Bassenge E, Pittler M and Hartmann BR: Effect of carbon dioxide-enriched water and fresh water on the cutaneous microcirculation and oxygen tension in the skin of the foot. Angiology 48: 337-343, 1997.

6. Liang J, Kang D, Wang Y, Yu Y, Fan J and Takashi E: Carbonate ion-enriched hot spring water promotes skin wound healing in nude rats. PLoS One 10: e0117106, 2015.

7. Jensen FB: Red blood cell pH, the Bohr effect, and other oxygenation-linked phenomena in blood $\mathrm{O}_{2}$ and $\mathrm{CO}_{2}$ transport. Acta Physiol Scand 182: 215-227, 2004.

8. Sakai Y, Miwa M, Oe K, Ueha T, Koh A, Niikura T, Iwakura T, Lee SY, Tanaka M and Kurosaka M: A novel system for transcutaneous application of carbon dioxide causing an 'artificial Bohr effect' in the human body. PLoS One 6: e24137, 2011.

9. Onishi Y, Kawamoto T, Ueha T, Kishimoto K, Hara H, Fukase N, Toda M, Harada R, Minoda M, Sakai Y, et al: Transcutaneous application of carbon dioxide $\left(\mathrm{CO}_{2}\right)$ induces mitochondrial apoptosis in human malignant fibrous histiocytoma in vivo. PLoS One 7: e49189, 2012.

10. Harada R, Kawamoto T, Ueha T, Minoda M, Toda M, Onishi Y, Fukase N, Hara H, Sakai Y, Miwa M, et al: Reoxygenation using a novel $\mathrm{CO}_{2}$ therapy decreases the metastatic potential of osteosarcoma cells. Exp Cell Res 319: 1988-1997, 2013.

11. Ueshima E, Yamaguchi M, Ueha T, Muradi A, Okada T, Idoguchi K, Sofue K, Akisue T, Miwa M, Fujii M, et al: Inhibition of growth in a rabbit VX2 thigh tumor model with intraarterial infusion of carbon dioxide-saturated solution. J Vasc Interv Radiol 25: 469-476, 2014.

12. Onishi Y, Kawamoto T, Ueha T, Hara H, Fukase N, Toda M, Harada R, Sakai Y, Miwa M, Nishida K, et al: Transcutaneous application of carbon dioxide $\left(\mathrm{CO}_{2}\right)$ enhances chemosensitivity by reducing hypoxic conditions in human malignant fibrous histiocytoma. J Cancer Sci Ther 04: 174-181, 2012.

13. Nagano T, Yasunaga M, Goto K, Kenmotsu H, Koga Y, Kuroda J, Nishimura Y, Sugino T, Nishiwaki Y and Matsumura Y: Synergistic antitumor activity of the SN-38-incorporating polymeric micelles NK012 with S-1 in a mouse model of non-small cell lung cancer. Int J Cancer 127: 2699-2706, 2010.

14. Vadász I, Dada LA, Briva A, Trejo HE, Welch LC, Chen J, Tóth PT, Lecuona E, Witters LA, Schumacker PT, et al: AMP-activated protein kinase regulates $\mathrm{CO}_{2}$-induced alveolar epithelial dysfunction in rats and human cells by promoting $\mathrm{Na}, \mathrm{K}-\mathrm{ATP}$ ase endocytosis. J Clin Invest 118: 752-762, 2008.

15. Summers BA, Overholt JL and Prabhakar NR: $\mathrm{CO}_{2}$ and $\mathrm{pH}$ independently modulate L-type $\mathrm{Ca}^{2+}$ current in rabbit carotid body glomus cells. J Neurophysiol 88: 604-612, 2002.

16. Iwabu M, Yamauchi T, Okada-Iwabu M, Sato K, Nakagawa T, Funata M, Yamaguchi M, Namiki S, Nakayama R, Tabata M, et al: Adiponectin and AdipoR1 regulate PGC-1 $\alpha$ and mitochondria by $\mathrm{Ca}^{2+}$ and AMPK/SIRT1. Nature 464: 1313-1319, 2010.

17. Irrcher I, Adhihetty PJ, Sheehan T, Joseph AM and Hood DA: PPARgamma coactivator-1 $\alpha$ expression during thyroid hormoneand contractile activity-induced mitochondrial adaptations. Am J Physiol Cell Physiol 284: C1669-C1677, 2003.

18. Ojuka EO, Jones TE, Han DH, Chen M and Holloszy JO: Raising $\mathrm{Ca}^{2+}$ in L6 myotubes mimics effects of exercise on mitochondrial biogenesis in muscle. FASEB J 17: 675-681, 2003.

19. Oe K, Ueha T, Sakai Y, Niikura T, Lee SY, Koh A, Hasegawa T, Tanaka M, Miwa M and Kurosaka M: The effect of transcutaneous application of carbon dioxide $\left(\mathrm{CO}_{2}\right)$ on skeletal muscle. Biochem Biophys Res Commun 407: 148-152, 2011. 
20. Montalto AS, Currò M, Russo T, Visalli G, Impellizzeri P, Antonuccio P, Arena S, Borruto FA, Scalfari G, Ientile R, et al: In vitro $\mathrm{CO}_{2}$-induced ROS production impairs cell cycle in SH-SY5Y neuroblastoma cells. Pediatr Surg Int 29: 51-59, 2013.

21. Takeda D, Hasegawa T, Ueha T, Imai Y, Sakakibara A, Minoda M, Kawamoto T, Minamikawa T, Shibuya Y, Akisue T, et al: Transcutaneous carbon dioxide induces mitochondrial apoptosis and suppresses metastasis of oral squamous cell carcinoma in vivo. PLoS One 9: e100530, 2014.

22. Fan Y and Bergmann A: The cleaved-caspase- 3 antibody is a marker of caspase-9-like DRONC activity in Drosophila. Cell Death Differ 17: 534-539, 2010.

23. Wang W, Lee NY, Georgi JC, Narayanan M, Guillem J, Schöder H and Humm JL: Pharmacokinetic analysis of hypoxia ${ }^{18} \mathrm{~F}$-fluoromisonidazole dynamic PET in head and neck cancer. J Nucl Med 51: 37-45, 2010.

24. Janssen HL, Haustermans KM, Balm AJ and Begg AC: Hypoxia in head and neck cancer: How much, how important? Head Neck 27: 622-638, 2005

25. Selfridge AC, Cavadas MA, Scholz CC, Campbell EL, Welch LC, Lecuona E, Colgan SP, Barrett KE, Sporn PH, Sznajder JI, et al: Hypercapnia suppresses the HIF-dependent adaptive response to hypoxia. J Biol Chem 291: 11800-11808, 2016.

26. Onnis B, Rapisarda A and Melillo G: Development of HIF-1 inhibitors for cancer therapy. J Cell Mol Med 13: 2780-2786, 2009.

27. Ai Z, Lu Y, Qiu S and Fan Z: Overcoming cisplatin resistance of ovarian cancer cells by targeting HIF-1-regulated cancer metabolism. Cancer Lett 373: 36-44, 2016.
28. Kandala PK and Srivastava SK: Diindolylmethane suppresses ovarian cancer growth and potentiates the effect of cisplatin in tumor mouse model by targeting signal transducer and activator of transcription 3 (STAT3). BMC Med 10: 9, 2012.

29. Caridi JG, Cho KJ, Fauria $\mathrm{C}$ and Eghbalieh N: Carbon dioxide digital subtraction angiography $\left(\mathrm{CO}_{2} \mathrm{DSA}\right)$ : A comprehensive user guide for all operators. Vasc Dis Manage 11: E221-E256, 2014.

30. Mladinich CR, Hawkins IF Jr, Heaton-Jones TG, Shiroma JT, Weingarten K, Kiehl A, Mays MB and Kublis P: Effects of carbon dioxide arterial infusion on hepatic biochemistry and histology in a rabbit model. Invest Radiol 30: 192-195, 1995.

31. Pascale F, Ghegediban SH, Bonneau M, Bedouet L, Namur J, Verret V, Schwartz-Cornil I, Wassef M and Laurent A: Modified model of VX2 tumor overexpressing vascular endothelial growth factor. J Vasc Interv Radiol 23: 809-817.e2, 2012

32. Buijs M, Vossen JA, Geschwind JF, Salibi N, Pan L, Ventura VP, Liapi E, Lee KH and Kamel IR: Quantitative proton MR spectroscopy as a biomarker of tumor necrosis in the rabbit VX2 liver tumor. J Vasc Interv Radiol 22: 1175-1180, 2011.

33. Wang H, Zheng LF, Feng Y, Xie XQ, Yang XM and Zhang GX: CTA combined with CT perfusion for assessing the efficacy of anti-angiogenic therapy in rabbit VX2 tumors. Acad Radiol 19: 358-365, 2012.

34. Winter JD, Akens MK and Cheng HL: Quantitative MRI assessment of VX2 tumour oxygenation changes in response to hyperoxia and hypercapnia. Phys Med Biol 56: 1225-1242, 2011. 